\title{
EXPERIMENTAL EVIDENCE SUPPORTING THE CONCEPTION OF "ADAPTATION ENERGY"
}

\author{
HANS SELYE \\ From the Department of Anatomy, Histology and Embryology, McGill University, \\ Montreal, Canada
}

Received for publication May 23, 1938

It has been shown that when an organism is exposed to a stimulus to the quality or intensity of which it is not adapted, it responds with a reaction which has been termed the "general adaptation syndrome" (Selye, 1936a, 1937a, 1938a). The symptoms of this syndrome have been described elsewhere (Harlow and Selye, 1937; Howlett and Browne, 1937; Karády et al., 1938; Schacher et al., 1937; Selye, 1936b, 1937b, 1937c; Selye et al., 1936). They are largely independent of the specific nature of the agent to which adaptation occurs, so that the reaction has been regarded as the somatic expression of damage as such. The general adaptation syndrome develops in three distinct stages which have been termed: 1 , the stage of the alarm reaction; 2 , the stage of resistance, and 3, the stage of exhaustion. The symptoms of the alarm reaction, among which thymus atrophy and adrenal hyperplasia are particularly conspicuous, disappear during the stage of resistance in spite of continued treatment with a uniform damaging stimulus (a drug, exposure to cold, excessive muscular exercise, etc.) but these same symptoms reappear during the so-called stage of exhaustion and finally death ensues. A similar three stage reaction was recently observed by Giragossintz and Sundstroem (1937) in rats kept under low oxygen tension. In these experiments, the loss of acquired adaptation during the stage of exhaustion is difficult to explain but as a working hypothesis, it was assumed that every organism possesses a certain limited amount of "adaptation energy" and once this is consumed, the performance of adaptive processes is no longer possible (Selye, 1938c).

Previous observations (Karády et al., 1938; Selye, 1938a, 1938b) showed that during the alarm reaction, the resistance of the organism is increased, not only to the stimulus with which the alarm reaction had been elicited but also to agents of a different nature. However during the second stage of the adaptation syndrome, this non-specific resistance vanishes rapidly at a time when the specific resistance to the agent with which the animal had been pretreated, is still very high. These findings 
are in accord with the conception of adaptation energy. Yet we must realize that this conception is quite contrary to common belief, since it is generally agreed that all vital processes are performed merely at the expense of the caloric energy of the ingested food. We felt, therefore, that further experimental evidence is required before one could regard it as proven that some principle not replaceable by food intake is expended during the process of adaptation. The two most important facts capable of proving that such a principle is utilized during adaptation and that the organism possesses only a limited amount of this "adaptation energy" are that acquired adaptation vanishes after a certain time and that while an organism builds up resistance against a certain agent it loses much of its ability to resist agents of a different nature. The object of this communication is to report on new experiments proving these points.

As we said above, a decrease in the weight of the thymus is a very sensitive index of damage caused by stimuli capable of eliciting an alarm reaction. We thought, therefore, that the weight of this organ would give us an objective indicator of the resistance to such stimuli. But the thymus involution produced by a stimulus during the alarm reaction may persist for quite some time even after the animal has entered into the stage of resistance, so that we had to devise a method by which one could establish resistance without first going through a marked initial stage of alarm. We found this to be possible if one uses gradually increasing doses of the alarming stimulus. Under these conditions, one may finally administer the "full alarming dose" (which has been defined as the dose just sufficient to produce a marked alarm reaction within 48 hours after the beginning of the experiment (Selye, 1937a)) without producing thymus involution. Animals thus treated are therefore led into the stage of resistance while they still possess a well developed thymus gland which may act as a sensitive indicator of the damage caused by various agents. Since short pretreatment with rapidly ascending doses would be insufficient to prevent an alarm reaction while prolonged pretreatment with very slowly ascending dosages may lead to the stage of exhaustion before the full alarming dose is reached, we performed a series of experiments, the purpose of which was to establish the optimum length of pretreatment which would prevent thymus involution following the administration of the full alarming dose of a stimulus. Table 1 gives an example of some experiments of this sort in which adrenaline was used as the damaging agent. The full "alarming dose" of this drug for a rat 3 months of age was found to be 0.2 cc. of a 1 per cent solution given subcutaneously twice daily during two subsequent days. In all these experiments we began treatment with $\frac{1}{4}$ of this dose and gradually raised it to the above mentioned amount which was then administered during the last two days. The italic numbers represent the average thymus weight of a group of 6 female rats, 3 months of age, the 
numbers in parentheses being the extreme variations observed. It will be remembered that all of these animals received during the last two days the same amount of adrenaline as the two day group which was simply treated with the full alarming dose without pretreatment. In the three day group (that is, one day pretreatment), or even more in the four day group (two days' pretreatment), the pretreatment actually increased the thymus involution elicited by the alarming dose administered during the last two days of the experiment. In these short run experiments, apparently the effect of the pretreatment was simply superimposed on that of the alarming dose, since there was not sufficient time for adaptation to develop. In the very chronic experiments, on the other hand, the effect of adaptation was lost because of exhaustion. The data show that in the case of adrenaline starting with one quarter of the alarming dose, the least damaging way of establishing resistance is to raise the daily amount to the full alarming dose within 5 to 12 days. If the daily dose is in-

TABLE 1

Importance of the length of treatment on establishing resistance of rats against adrenaline

\begin{tabular}{c|c}
\hline PERIOD of TREATMENT & THYMUS waighT \\
\hline days & mgm. \\
2 & $127,(107,205)$ \\
3 & $100,(73,126)$ \\
4 & $80,(54,150)$ \\
5 & $180,(112,227)$ \\
8 & $230,(180,254)$ \\
12 & $174,(90,250)$ \\
23 & $148,(75,248)$ \\
\hline
\end{tabular}

creased either more rapidly or more slowly than this, the results are less satisfactory.

Using animals optimally pretreated in this manner, we were able to show in a large number of experiments that in the stage of resistance, the stimulus to which adaptation occurred produces little or no thymus involution, while other stimuli may cause an even more marked involution in these resistant animals than they do in not pretreated controls. We shall not report on all the experiments of this series but we wish to describe one as an example.

The experiment was so planned that all the animals were three months old at the end of the pretreatment, that is, at the time when they received the full alarming dose of the stimulus for which they had been adapted. The full alarming dose as defined above, for the drugs used here and for rats 3-4 months of age is: $0.2 \mathrm{cc}$. of 1 per mille solution of adrenaline hydrochloride; $0.5 \mathrm{cc}$. of a 4 per cent solution of formaldehyde; $2 \mathrm{cc}$. of a 1 
per cent solution of morphine sulphate and 2 cc. of 1 per cent solution of atropine sulphate given subcutaneously twice daily on two consecutive days.

For the sake of uniformity only female rats were used in this series, although other experiments (not reported here) show that adaptation occurs in males in a very similar manner. Each group consisted of 24 rats. One group had been adapted to morphine, one to adrenaline and one to atropine. In all these groups, one quarter of the alarming dose of the respective drug was given to start with, and this amount was gradually raised to the full alarming dose within 10 days. A fourth group had been adapted to muscular exercise, starting with 10 minutes twice daily in revolving cages with a diameter of 12 inches and running at a speed of 18 to 22 revolutions per minute. The amount of exercise was increased daily, so that at the end of three weeks, the animals were able to run one and one-half hours twice daily without any difficulty. Previous experiments had shown that this is the full alarming dose for exercise. In this group it proved necessary to give a somewhat longer pretreatment than in the others. The fifth group had been adapted to cold by gradually decreasing the surrounding temperature to $-4^{\circ} \mathrm{C}$. within 10 days. Two days spent at a temperature of about $-4^{\circ} \mathrm{C}$. represents the full alarming dose for cold. As soon as the full alarming dose of these five stimuli had been reached, each series was subdivided into groups of 6 animals. One of these groups was exposed to the full alarming dose of the stimulus to which they had been adapted and the other three to a stimulus of a different nature. At the same time, a group of 6 not pretreated control animals was exposed to the full alarming dose of each of these stimuli. In the atropine pretreated series, six animals died during pretreatment so that only three groups were left for the final test. It is evident from the data summarized in table 2 that pretreatment with a certain alarming stimulus increases the resistance to this particular stimulus above that of not pretreated animals, but simultaneously decreases the resistance to alarming stimuli of a different type. This was especially obvious in the case of inurement to more physiological stimuli, such as muscular exercise or cold, to which more complete and more lasting habituation is obtained than to drugs.

In order to avoid the skin lesions which usually result from chronic subcutaneous administration of atropine, the drug was given intraperitoneally in this experiment in which prolonged pretreatment was necessary. For the sake of uniformity this method of administration was also used in the groups receiving atropine after pretreatment with another drug. While the atropine pretreated animals stood these daily intraperitoneal injections of atropine without ill effects, it became evident during the experiments that this same dose of atropine given intraperitoneally is fatal 
for not pretreated animals. However the not pretreated animals survived this dose longer than the animals adapted to other stimuli, while there

TABLE 2

Showing that while adaptation is acquired to a certain stimulus the resistance of rats to other stimuli decreases

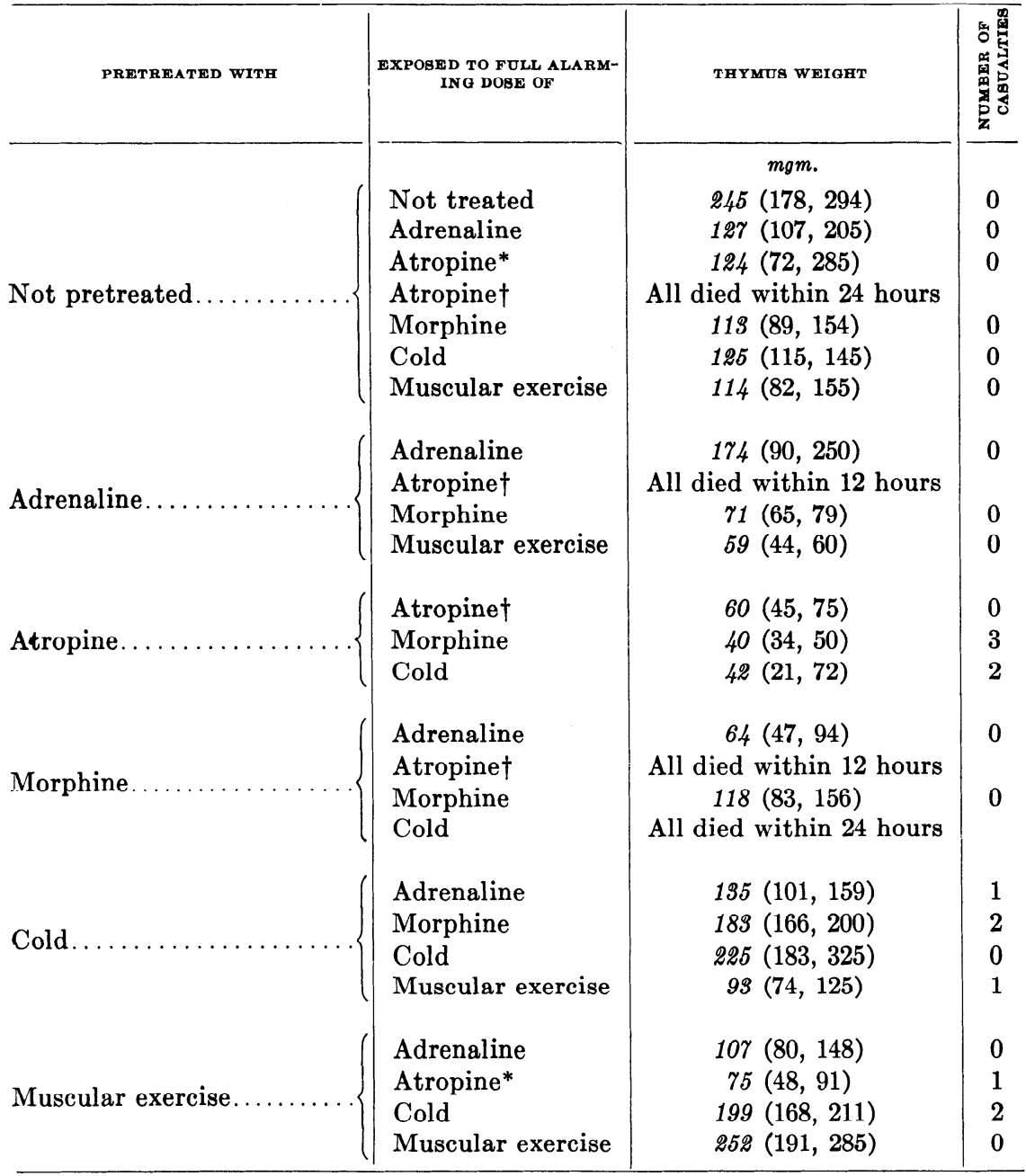

* Subcutaneously.

$\dagger$ Intraperitoneally.

were no casualties at all in the group which had been previously adapted to this drug. Thus this experiment also supports the conception of the specificity of adaptation although the thymus weights gave us no information 
regarding this point since many of the animals died before thymus atrophy could have occurred. It appears from the data of this table that habituation even to such physiological stimuli as muscular exercise or cold is acquired at some expense-namely, at the expense of adaptation energyso that animals adapted to such stimuli lose much of their natural innate ability to adapt themselves to a stimulus of a different type.

In order to obtain more explicit proof that such specific adaptation is connected with a decrease in the ability of animals to survive lethal doses of other drugs, another series of experiments was performed in which the number of survivals in a certain group was taken as an index of resistance instead of the thymus weight.

Twelve female rats, three and one-half months old, were pretreated with ascending doses of morphine sulphate, beginning with $2 \mathrm{cc}$. of a 1 per cent solution subcutaneously twice daily, the dose being gradually increased within 19 days to $2 \mathrm{cc}$. of a 3 per cent solution 3 times daily. The animals were then divided into two groups. In 6 rats treatment with the same dose of morphine was continued, while the remaining 6 received a single injection of $0.25 \mathrm{cc}$. of a 2.5 per cent solution of alpha dinitrophenol, in Mazola oil, subcutaneously; the same dose of dinitrophenol was also administered to 6 not pretreated controls. All the morphine pretreated animals died within two and one-half hours after the injection of the dinitrophenol, while only one of the not pretreated controls succumbed during this time. (They all succumbed after two more injections of the same magnitude given during the same day.) The resistance to dinitrophenol was decreased, therefore, by the morphine pretreatment. That the resistance towards morphine was actually increased above normal in the dinitrophenol sensitive rats is shown by the fact that the remaining 6 tolerated $2 \mathrm{cc}$. of a 3 per cent morphine solution 3 times daily without casualties or even very marked symptoms of morphine intoxication, while 3 out of 6 not pretreated controls which received this dose of morphine daily died within four days. Autopsy disclosed typical symptoms of the alarm reaction. The results of this experiment are summarized in table 3 (expt. I).

That resistance to dinitrophenol may also be acquired was shown in another group of 6 rats of the same age and sex receiving ascending daily doses of this drug for 8 days. At the end of this period they tolerated $0.25 \mathrm{cc}$. of the 2.5 per cent solution 4 times a day for 4 consecutive days without casualties. This shows a definite increase in the resistance as compared with the not pretreated controls mentioned above, of which none tolerated even as much as 3 injections given in one day (table 3 , expt. 2).

In another series, two months old male rats were used. Twelve animals were adapted to atropine (15 days' pretreatment with daily doses as- 
cending from $1 \mathrm{cc}$. of the 2 per cent solution to 2 cc. twice daily intraperitoneally) and 18 to adrenaline (15 days' pretreatment with daily doses ascending from $0.2 \mathrm{cc}$. of 1 per mille solution subcutaneously to $0.3 \mathrm{cc}$, 3 times daily). Six adrenaline pretreated animals were treated with 0.3 cc. of a 1 per mille solution of adrenaline 3 times daily, together with 6 not pretreated animals. While all the adrenaline pretreated animals survived, 3 of those not pretreated succumbed within 96 hours. After the acquisition of adaption to adrenaline was thus ascertained, the remaining 6 adrenaline adapted animals were treated with 2 cc. of a 2 per cent solution of atropine twice daily, together with 6 atropine pretreated and 6 not pretreated controls. All adrenaline pretreated animals succumbed within

TABLE 3

Showing that while adaptation is acquired to a certain stimulus the resistance of rats to other stimuli decreases

\begin{tabular}{|c|c|c|c|}
\hline $\begin{array}{l}\text { NUMBER OF } \\
\text { EXPERIMENT }\end{array}$ & PRETREATMENT & TREATMENT & $\begin{array}{c}\text { NUMBERR OF } \\
\text { CABUALTIMS } \\
\text { IN GROUP OF } 6\end{array}$ \\
\hline 1 & $\begin{array}{l}\text { Morphine } \\
\text { Morphine } \\
\text { Not pretreated } \\
\text { Not pretreated }\end{array}$ & $\begin{array}{l}\text { Dinitrophenol* } \\
\text { Morphine } \\
\text { Dinitrophenol } \\
\text { Morphine }\end{array}$ & $\begin{array}{l}6 \\
0 \\
1 \\
3\end{array}$ \\
\hline 2 & $\begin{array}{l}\text { Dinitrophenol } \\
\text { Not pretreated }\end{array}$ & $\begin{array}{l}\text { Dinitrophenol } \\
\text { Dinitrophenol }\end{array}$ & $\begin{array}{l}0 \\
6\end{array}$ \\
\hline 3 & $\begin{array}{l}\text { Adrenaline } \\
\text { Not pretreated } \\
\text { Adrenaline } \\
\text { Atropine } \\
\text { Not pretreated } \\
\text { Adrenaline } \\
\text { Not pretreated }\end{array}$ & $\begin{array}{l}\text { Adrenaline } \\
\text { Adrenaline } \\
\text { Atropine } \\
\text { Atropine } \\
\text { Atropine } \\
\text { Formaldehyde } \\
\text { Formaldehyde }\end{array}$ & $\begin{array}{l}0 \\
3 \\
6 \\
0 \\
2 \\
6 \\
1\end{array}$ \\
\hline
\end{tabular}

* The dose of dinitrophenol used in experiment 1 is smaller than that employed in experiment 2 (see text).

32 hours after the first injection, while only 2 of the not pretreated and none of the atropine pretreated succumbed during this time.

The remaining 6 adrenaline pretreated rats received 0.5 cc. of a 4 per cent solution of formaldehyde subcutaneously 3 times daily, together with 6 not pretreated controls of the same age and sex. While all the adrenaline pretreated animals died within 35 hours after the first injection, only one of the not pretreated rats succumbed during this time (table 3, expt. 3).

All these experiments corroborate the conception that the adaptation acquired in the stage of resistance is specific and that while adaptation occurs to a certain drug the organism exhausts its abilities to adapt itself to others. That means that adaptation is always acquired at a cost. 


\section{SUMMARY AND CONCLUSIONS}

The experiments reported in this communication show that by giving gradually increasing doses of various alarming stimuli, one may raise the resistance of animals in such a manner that even treatment which would cause marked thymus involution in normals will have little or no effect on the thymus weight. On the other hand, stimuli other than the one with which these animals had been pretreated will cause severe thymus involution which is usually even more pronounced than that obtained by the same dose of the same agent in the not pretreated animal. Using the response of the thymus as an index of resistance, one may say, therefore, that during adaptation to a certain stimulus the resistance to other stimuli decreases.

This conception receives further support by experiments showing that rats pretreated with a certain agent will resist such doses of this agent which would be fatal for not pretreated controls. At the same time, their resistance to toxic doses of agents other than the one to which they have been adapted decreases below the initial value.

These findings are tentatively interpreted by the assumption that the resistance of the organism to various damaging stimuli is dependent on its adaptability. This adaptability is conceived to depend upon adaptation energy of which the organism possesses only a limited amount, so that if it is used for adaptation to a certain stimulus, the resistance to other stimuli will necessarily decrease. We conclude that adaptation to any stimulus is always acquired at a cost, namely, at the cost of adaptation energy.

\section{REFERENCES}

Giragossintz, G. and E. S. Sundstromm. Proc. Soc. exper. Biol. and Med. 36: $432,1937$.

Harlow, C. M. and H. Selye. Proc. Soc. exper. Biol. and Med. 36: 141, 1937.

Howlett, J. ANd J. S. L. Browne. Canadian M. A. J. 37: 288, 1937.

Karady, S., J. S. L. Browne and H. Selye. Quart. J. Physiol. (in press).

Schacher, J., J. S. L. Browne ANd H. Selye. Proc. Soc. exper. Biol. and Med. 36: $488,1937$.

Selye, H. Nature 138: 32, 1936a.

British J. exper. Pathol. 17: 234, 1936 b.

Endocrinology 21: 169, 1937a.

Canadian M. A. J. 36: 462, 1937b.

Arch. Internat. de Pharm. dynamie et de Thérap. 55: 431, $1937 \mathrm{c}$.

Klin. Wchnschr. 666, 1938a.

This Journal 122: 347, 1938b.

Nature 141: 926, $1938 \mathrm{c}$.

Selye, H., C. M. Harlow and J. B. Collip. Endokrinol. 18: 81, 1936. 